\title{
Crystallization Kinetics and Morphology in Miscible Blends of Two Crystalline Polymers
}

\author{
Jeong-Chang LeE, ${ }^{\dagger}$ Hare TaZawa, Takayuki IkeHaRA, \\ and Toshio NisHI \\ Department of Applied Physics, School of Engineering, The University of Tokyo, \\ Bunkyo-ku, Tokyo 113-8656, Japan
}

(Received December 8, 1997)

\begin{abstract}
Miscibility, crystallization behavior and morphology of blends prepared from two crystalline polymers, poly(butylene succinate) (PBSU), and poly(vinylidene chloride- $c o$-vinyl chloride) [P(VDC-VC)] have been examined by polarized optical microscopy and differential scanning calorimetry. It is found that PBSU is miscible with P(VDC-VC) since each blend showed a single glass transition temperature $T_{\mathrm{g}}$. Spherulitic morphology and the melting behavior of the blends were strongly dependent upon the crystallization kinetics and some unique phenomena were found out: (i) in contrast to the other results reported so far, growth rate $G$ of low- $T_{\mathrm{m}}$ component (PBSU) was decreased greatly with increasing high- $T_{\mathrm{m}}$ component $[\mathrm{P}(\mathrm{VDC}-\mathrm{VC})]$ content, (ii) for the PBSU/P(VDC-VC) $(40: 60)$ blend crystallized at $90^{\circ} \mathrm{C}$ (i.e., the growth rate of the two components was appproximately the same) so called interlocked spherulites were formed, where PBSU spherulites grown through the interlamellar regions of $\mathrm{P}(\mathrm{VDC}-\mathrm{VC})$ spherulites, (iii) for the blends crystallized during fast cooling conditions from the melt (e.g., faster than $10^{\circ} \mathrm{C} \mathrm{min}{ }^{-1}$ ), only one melting peak appeared corresponding to PBSU and no noticeable melting peaks of high- $T_{\mathrm{m}}$ component $\mathrm{P}(\mathrm{VDC}-\mathrm{VC})$ were observed. Hence, it is seen that the crystallization behavior of high- $T_{\mathrm{m}}$ component is heavily affected by the low- $T_{\mathrm{m}}$ component. Therefore, kinetic factors are the most important one in controlling the crystallization behavior and the morphology of the crystalline/crystalline blends.

KEY WORDS Poly(butylene succinate) / Poly(vinylidene chloride-co-vinyl chloride) / Polymer Blend / Spherulitic Morphology / Crystallization Kinetics /
\end{abstract}

Miscibility between two amorphous polymers have been studied intensively by many researchers, especially in relation to phase separation dynamics. Miscibility between crystalline and amorphous polymers has also been examined, and a number of miscible blends are known. ${ }^{1-9}$ On the other hand, few studies have been reported on the miscibility and crystallization behavior of polymer blends between two crystalline polymers. A miscible crystalline/crystalline polymer blend is a rare phenomenon and only a few pairs have been reported to form miscible systems [e.g., poly( $\varepsilon$-caprolactone) (PCL)/poly(vinylidene chloride) ${ }^{10,11}$ poly(3-hydroxybutyrate) (PHB)/poly(ethylene oxide) (PEO), ${ }^{12} \mathrm{PHB} /$ poly(L-lactide $\left.)^{13}\right]$. This is because the crystalline polymer pairs having attractive interactions between the two components are very rare. Manley et al. ${ }^{14-17}$ recently have reported a series of miscibility and crystallization behavior of poly(1,4-butylene adipate) (PBA) and poly(vinylidene fluoride) (PVDF) where both constituents are crystalline polymers. In the PBA/PVDF blends, the melting points of the two components have been $c a$. $100^{\circ} \mathrm{C}$ apart, the crystallization behavior and morphology of the low- $T_{\mathrm{m}}$ component (PBA) are seriously influenced by the presence of the spherulitic microstructure of the high- $T_{\mathrm{m}}$ component (PVDF).

Recently, we have reported miscibility and crystallization behavior of the mixture of poly(butylene succinate) (PBSU) and poly(vinylidene fluoride) (PVDF). ${ }^{18}$ In the PBSU/PVDF blends, similar miscibility and phase behavior are observed as in the case of PBA/PVDF blends because PBSU also has carbonyl groups which interact with PVDF. However, PBSU/PVDF blends have less difference in $T_{\mathrm{m}}\left(c a .45^{\circ} \mathrm{C}\right)$ than that of the blends in PBA/PVDF. The nucleation frequency of PBSU is very low (this leads to a formation of very large spherulites) and the spherulitic growth rate of PBSU is faster than that of PVDF. Then, it is possible to observe the crystallization behavior and spherulitic morphology of the low- $T_{\mathrm{m}}$ component (PBSU). The crystallization and melting behavior of low- $T_{\mathrm{m}}$ component PBSU are quite different from that of high- $T_{\mathrm{m}}$ component PVDF: (i) the magnitude of the melting point depression of PBSU is changed strongly with cooling rates (the faster the cooling speed of the blends, the larger the magnitude of the melting point depression of the PBSU, whereas that of the PVDF is almost unchanged), (ii) in isothermal crystallization, the melting point of PBSU is increased with increase in PVDF content for a given $T_{\mathrm{c}}$, in contrast to the decrease of the melting point in usual amorphous/ crystalline blends, (iii) the spherulitic growth rate $G$ of PBSU is decreased very slightly with increase in PVDF content at a given $T_{\mathrm{c}}$ and the morphologies of the PBSU crystals are strongly dependent upon the crystallization conditions. These results imply that the kinetic factor of the crystallization is very important in crystalline/crystalline polymer blends. The crystallization behavior and morphology of a crystalline component in the crystalline/crystalline polymer blends should be quite different from those of the crystalline component in the amorphous/crystalline blends.

In this study, we have chosen the mixture of PBSU/ poly(vinylidene chloride-co-vinyl chloride) [P(VDCVC)] as a model crystalline/crystalline polymer system. We choose this crystalline polymer pair because (i) these

${ }^{\dagger}$ To whom all correspondence should be addressed.

Present address: Du Pont-Mitsui Fluorochemicals Co., Ltd. 3600 Miho, Shimizu, Shizuoka 424-8631, Japan. 
Table I. Molecular characteristics, sources, and codes of the polymers

\begin{tabular}{|c|c|c|c|c|c|c|}
\hline Polymer & Code & Source & $\begin{array}{l}\text { Molecular } \\
\text { weight }\end{array}$ & $\frac{T_{\mathrm{g}}}{{ }^{\circ} \mathrm{C}}$ & $\frac{T_{\mathrm{m}}}{{ }^{\circ} \mathrm{C}}$ & $\frac{G_{\max }{ }^{\mathrm{b}}}{\mu \mathrm{m} \mathrm{s}^{-1}}$ \\
\hline $\begin{array}{l}\text { Poly(vinylidene chloride-co-vinyl } \\
\text { chloride) }(80: 20)\end{array}$ & $\mathrm{P}(\mathrm{VDC}-\mathrm{VC})$ & $\begin{array}{l}\text { Asahi } \\
\text { Kasei }\end{array}$ & $100000\left(M_{w}\right)$ & 7 & 148 & $0.01^{\mathrm{d}}$ \\
\hline
\end{tabular}

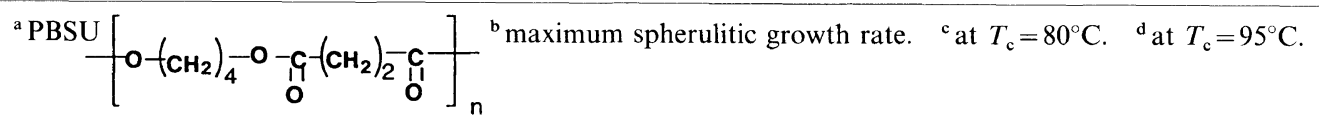

blends are supposed to form thermodynamically miscible mixture as in the case of other polyester/poly(vinylidene halide) blends, ${ }^{9-11,14-18}$ (ii) the blends have less difference in $T_{\mathrm{m}}\left[\mathrm{ca} .115^{\circ} \mathrm{C}\right.$ for PBSU and $\mathrm{ca} .150^{\circ} \mathrm{C}$ for $\mathrm{P}(\mathrm{VDC}-\mathrm{VC})]$ than that of the other blends reported, ${ }^{10-14}$ (iii) the spherulitic growth rate of low- $T_{\mathrm{m}}$ component PBSU is much faster than that of high- $T_{\mathrm{m}}$ component P(VDC-VC), (iv) these polymers are crystallizable almost over the same range of temperatures (from ca. $70^{\circ} \mathrm{C}$ to $c a \cdot 105^{\circ} \mathrm{C}$ ). Therefore, low $-T_{\mathrm{m}}$ component PBSU can crystallize with a spherulitic morphology although the crystalline phase of the high- $T_{\mathrm{m}}$ component $\mathrm{P}$ (VDC-VC) exists in the blend, while it is impossible in the other crystalline/crystalline blends. In this sense, PBSU/P(VDC-VC) blends are useful in investigating the effect of kinetic factors on the crystallization and morphology of the blends because the spherulitic growth rate of the low- $T_{\mathrm{m}}$ component PBSU plays very important role in the overall crystallization of the blends. In this PBSU/P(VDC-VC) blends, there can exist much more complex morphologies.

Therefore, the main focus of this article is to investigate the effect of crystallization kinetics on the crystallization behavior and the morphology of the blends. It is found that the PBSU/P(VDC-VC) blend is thermodynamically miscible because these blends show composition dependent single glass transition temperatures. The crystallization behavior and morphology of the blends are strongly dependent upon the crystallization kinetics. For a specific crystallization condition, the crystallization behavior and morphology of the high- $T_{\mathrm{m}}$ component $\mathrm{P}(\mathrm{VDC}-\mathrm{VC})$ is governed by the low $-T_{\mathrm{m}}$ component PBSU, while the crystallization behavior and morphology of the blends in the previous reports ${ }^{10-15}$ have been always influenced mainly by the high- $T_{\mathrm{m}}$ component. To our knowledge, this article is the first finding that the low- $T_{\mathrm{m}}$ component is also capable of governing the overall crystallization behavior and morphology of crystalline/crystalline polymer blends.

\section{EXPERIMENTAL}

\section{Materials and Sample Preparation}

A list of the polymers used in this study is shown in Table I. P(VDC-VC) is a random copolymer of vinylidene chloride containing $20 \%$ vinyl chloride as a comonomer. The PBSU/P(VDC-VC) blends were prepared with a mutual solvent $N, N$-dimethylformamide (DMF) at an elevated temperature. After the solvent was removed at room temperature, the samples were kept in a vacuum at $20^{\circ} \mathrm{C}$ for a week.

\section{Microscopic Observation}

To study the morphology of the blends and the spherulitic growth rate of the PBSU and P(VDC-VC) spherulites, samples cast on cover-glasses were observed under a polarizing microscope (OLYMPUS BHAP) equipped with a temperature controller (LINKAM $\mathrm{TH}-600)$. The samples were heated to $170^{\circ} \mathrm{C}$ for $10 \mathrm{~min}$ and then rapidly cooled to the crystallization temperature $T_{\mathrm{c}}$. The diameter of the growing spherulite was measured as a function of time by taking photographs during crystallization. Since the spherulites of P(VDC-VC) were so small and the birefringent contrast of $\mathrm{P}(\mathrm{VDC}-\mathrm{VC})$ was very weak, it was difficult to observe the spherulitic morphology of P(VDC-VC) in the blends with conventional polarizing optical microscope. Therefore, we observed the spherulitic morphology of the blends by placing a sensitive-tint retardation plate in the beam at $45^{\circ}$ to the directions of the crossed polarizer and analyzer. The PBSU and P(VDC-VC) spherulites were found to have opposite sign of birefringence, which were useful for the observation of their spherulitic growth.

\section{Differential Scanning Calorimetry (DSC)}

The glass transition temperature $T_{\mathrm{g}}$ and the melting point $T_{\mathrm{m}}$ of the samples were determined by TA Instruments DSC 2910 with a Thermal Analyst 2000. For the determination of $T_{\mathrm{g}}$, solution-cast samples were heated to $170^{\circ} \mathrm{C}$ for $10 \mathrm{~min}$ and quenched to $-100^{\circ} \mathrm{C}$ using liquid nitrogen followed by heating at $10^{\circ} \mathrm{C} \mathrm{min}^{-1}$. The value of $T_{\mathrm{g}}$, was determined as the temperature of the half-height of the heat capacity jump. The melting temperature $T_{\mathrm{m}}$ of the solution-cast samples were obtained by heating the sample to $170^{\circ} \mathrm{C}$ at $20^{\circ} \mathrm{C} \mathrm{min}^{-1}$. The value of $T_{\mathrm{m}}$ was taken as the peak temperature of the DSC melt peak.

To investigate the effect of the crystallization kinetics on the overall crystallization behavior of the blends, we crystallized the blends under various crystallization conditions and measured the melting points of the two components. To study the effect of slow crystallization conditions, the samples were maintained at $170^{\circ} \mathrm{C}$ for $10 \mathrm{~min}$ to ensure complete melting of the two PBSU and $\mathrm{P}$ (VDC-VC) crystals before being cooled at $10^{\circ} \mathrm{C} \mathrm{min}^{-1}$ or $1^{\circ} \mathrm{C} \mathrm{min}{ }^{-1}$ to room temperature. During this cooling process, crystallization of the two components occurred simultaneously because two constituent polymers are crystallizable almost over the same range of temperatures (from $c a .70^{\circ} \mathrm{C}$ to $c a .105^{\circ} \mathrm{C}$ ). After the samples were 


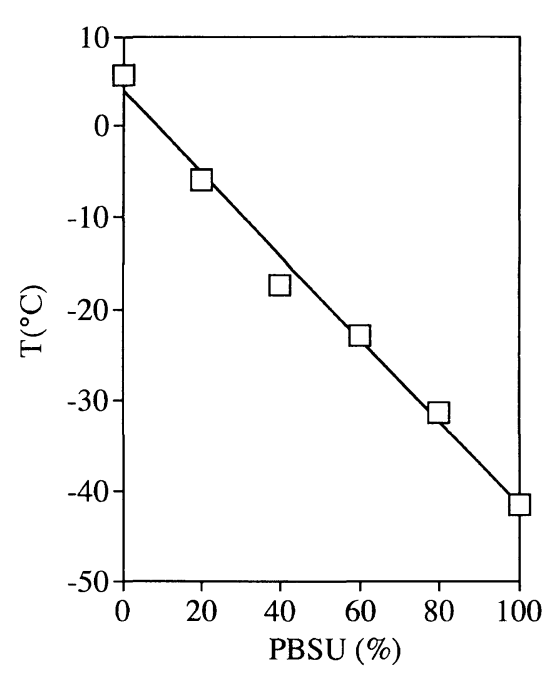

Figure 1. Dependence of $T_{\mathrm{g}}$ of the solution-cast PBSU/P(VDC-VC) blends on the weight fraction of PBSU. The solid line is drawn according to eq 1 .

cooled to room temperature, blends were heated to $170^{\circ} \mathrm{C}$ at a heating rate of $20^{\circ} \mathrm{C} \mathrm{min}^{-1}$ for the observation of their melting behavior. A cooling rate of $100^{\circ} \mathrm{C} \mathrm{min}^{-1}$ was used for the effect of fast crystallization conditions. In this fast cooling condition, only PBSU component could crystallize because the crystallization speed of $\mathrm{P}(\mathrm{VDC}-\mathrm{VC})$ was so slow that P(VDC-VC) has no time to crystallize. To study the cold crystallization of the blends, the samples were quenched in a liquid nitrogen after maintaining at $170^{\circ} \mathrm{C}$ for $10 \mathrm{~min}$. After the quenching was completed, the samples were moved to DSC cell maintained at $-80^{\circ} \mathrm{C}$ and heated at a heating rate of $20^{\circ} \mathrm{Cmin}^{-1}$. During this heating process, crystallization and melting behavior were observed. The melting behavior of isothermally crystallized blends was also analyzed by DSC. The samples were melted at $170^{\circ} \mathrm{C}$ for $10 \mathrm{~min}$, then rapidly cooled to the desired crystallization temperature $T_{\mathrm{c}}$. After crystallization they were heated above the melting point at a scanning rate of $20^{\circ} \mathrm{C} \mathrm{min}^{-1}$.

\section{RESULTS AND DISCUSSION}

\section{$T_{\mathrm{g}}$ and $T_{\mathrm{m}}$ of the Solution-Cast Blends}

Figure 1 shows the dependence of $T_{\mathrm{g}}$ on the composition of the PBSU/P(VDC-VC) blends. All the blends showed a single $T_{\mathrm{g}}$ whose values were intermediate between those of the pure components. The experimental values of $T_{\mathrm{g}}$ are plotted against PBSU content. These results are satisfactorily presented by the Fox equation ${ }^{19}$

$$
\frac{1}{T_{\mathrm{g}}}=\frac{w_{1}}{T_{\mathrm{g} 1}}+\frac{w_{2}}{T_{\mathrm{g} 2}},
$$

where $T_{\mathrm{g}}, T_{\mathrm{g} 1}$, and $T_{\mathrm{g} 2}$ are the glass transition temperatures of the blend, PBSU, and P(VDC-VC) respectively, and $w_{1}, w_{2}$ are the weight fraction of PBSU and $\mathrm{P}(\mathrm{VDC}-\mathrm{VC})$. The composition dependent single $T_{\mathrm{g}}$ shows that these blends are miscible.

Figure 2 shows the DSC melting curves of solution-cast PBSU/P(VDC-VC) blends. Since PBSU/P(VDC-VC) blends have dissimilar chemical structure, the two crystalline components formed segregated crystals. The

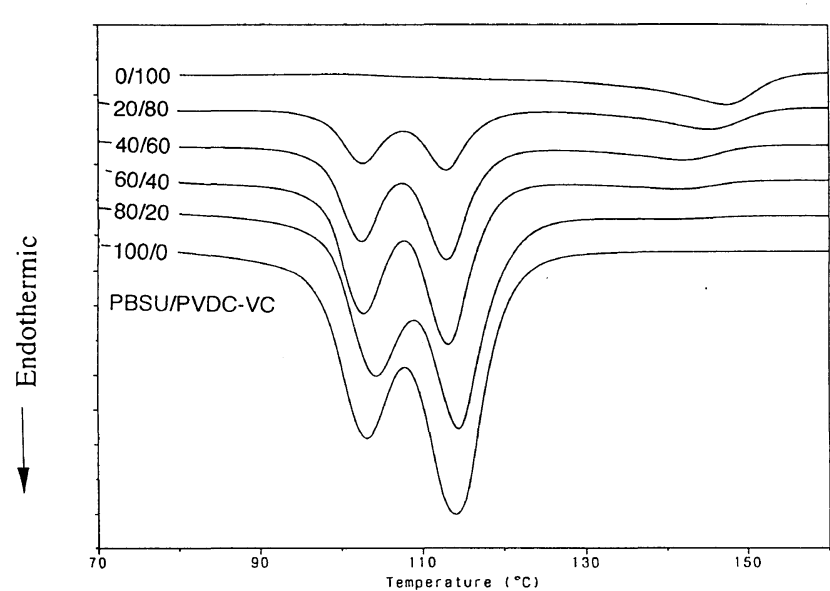

Figure 2. DSC melting endotherms of solution-cast PBSU/P(VDCVC) blends. Each crystalline component formed segregated crystals. Scan rate was $20^{\circ} \mathrm{C} \mathrm{min}^{-1}$.

higher and the lower melting peaks are attributed to the melting of P(VDC-VC) and PBSU, respectively. All the blends containing PBSU showed two melting peaks of PBSU. This double melting behavior is frequently found in miscible blends containing biodegradable aliphatic polyesters, such as PHB or PBSU prepared by casting from solvent. ${ }^{12,18}$ However, the blends crystallized from the melt showed only a single peak that corresponds to the higher temperature peak (see Figure 11). Therefore we report the higher melting peak of PBSU here. Table II shows how the $T_{\mathrm{m}}$ of each component depends on the weight fraction of the other component. The $T_{\mathrm{m}}$ for each component decreased with increasing the fraction of the other component. However, the melting point depression of low- $T_{\mathrm{m}}$ component (PBSU) was smaller than that of high- $T_{\mathrm{m}}$ component [P(VDC-VC)]. For the fact that the depression of $T_{\mathrm{m}}$ of PBSU was very small, we can consider the casting temperature of the blends. The blend solution was cast at an elevated temperature $\left(c a .120^{\circ} \mathrm{C}\right)$ and, at this temperature, the $\mathrm{P}(\mathrm{VDC}-\mathrm{VC})$ starts to crystallize, whereas the PBSU cannot crystallize at this high temperature (see Figures 4 and 5). Since the crystallization behavior of each component in crystalline/crystalline polymer blends is strongly dependent upon the crystallization kinetics (i.e., cooling rates from the melt), we compared the effect of cooling rates on the melting point of each component and these results will be discussed in a later section.

\section{Spherulitic Growth Rate and Morphology of PBSU}

In general, the observation of the spherulitic growth of low- $T_{\mathrm{m}}$ component in crystalline/crystalline blend is very difficult because the low- $T_{\mathrm{m}}$ component must crystallize in the matrix of high- $T_{\mathrm{m}}$ component crystals. Therefore, only tiny crystals of low- $T_{\mathrm{m}}$ component can grow in the interlamellar regions of the high- $T_{\mathrm{m}}$ component spherulites. Although the spherulitic growth rates of high- $T_{\mathrm{m}}$ component were reported in several crystalline/crystalline blend (e.g., $\mathrm{PCL} / \mathrm{PVDC},{ }^{10,11} \mathrm{PHB} /$ $\mathrm{PEO},{ }^{12}$ and $\mathrm{PBA} / \mathrm{PVDF}^{15}$ ), the observations of the spherulitic morphologies of the low- $T_{\mathrm{m}}$ component were unsuccessful.

In our previous study with PBSU/PVDF blends, ${ }^{18}$ however, the observation of the low $-T_{\mathrm{m}}$ component, 

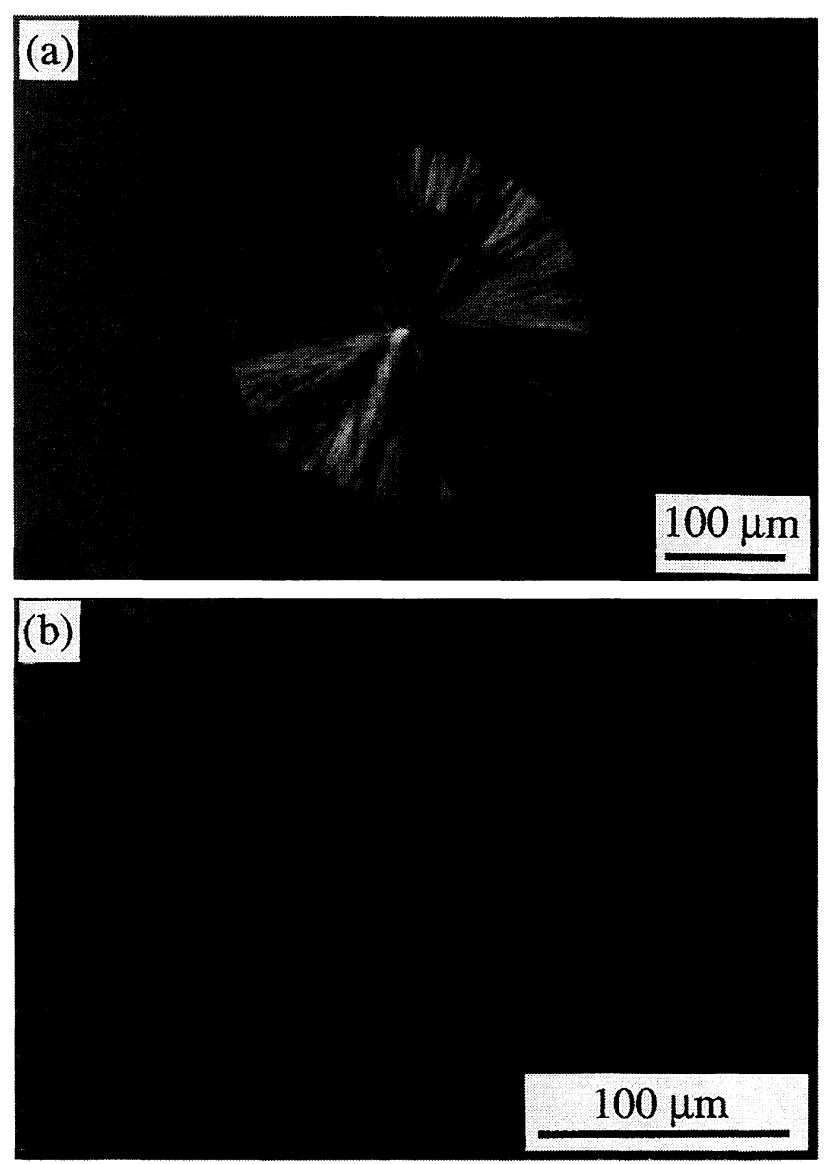

Figure 3. Spherulitic morphologies of the pure PBSU and $\mathrm{P}(\mathrm{VDC}$ VC). (a) PBSU $100 \%, T_{\mathrm{c}}=90^{\circ} \mathrm{C}$; (b) $\mathrm{P}(\mathrm{VDC}-\mathrm{VC}) 100 \%, T_{\mathrm{c}}=90^{\circ} \mathrm{C}$. The scale is different for each micrograph.

PBSU, was possible because the nucleation frequency of PBSU remained very low in spite of the presence of the PVDF crystals and the PBSU spherulite grows very fast compared to PVDF. This led to large spherulites of PBSU which were grown in the order of several millimeters. In the present study with PBSU/P(VDC-VC) blends, the observation of the spherulitic morphologies of the low $-T_{\mathrm{m}}$ component (PBSU) was also possible because the spherulitic growth rate of PBSU was $c a$. one hundred times as fast as that of P(VDC-VC) and the size of PBSU spherulite was much larger than P(VDC-VC) (see Figure 3).

The diameter $D$ of isothermally crystallized spherulites of PBSU increased linearly with crystallization time. The growth rate $G$ was calculated as $G=\mathrm{d} D / \mathrm{d} t$ for various crystallization temperature $T_{\mathrm{c}}$. The results for different $\mathrm{P}(\mathrm{VDC}-\mathrm{VC})$ contents are shown in Figure 4. The value of $G$ was independent of the size of the spherulites during the crystallization. This fact suggests that the P(VDC$\mathrm{VC}$ ) component remained in the interlamellar regions of the PBSU spherulites, and was not excluded from these spherulites. However, for the blends containing less than $40 \%$ PBSU, the PBSU spherulites were in irregular shape and it was impossible to measure the diameter of PBSU spherulites. No extinction bands were observed in the blends.

In PBSU/PVDF blends, ${ }^{18}$ the growth rate $G$ of PBSU decreased very slightly with PVDF content. The growth rate of the blends containing $80 \%$ PBSU was almost the same as that of pure PBSU. We explained such a small

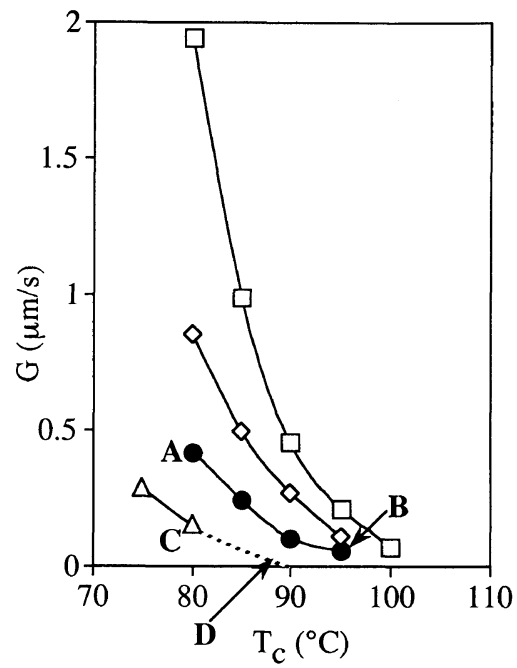

Figure 4. Spherulitic growth rate $G$ of PBSU $v s$. crystallization temperature $T_{\mathrm{c}}$ for PBSU/P(VDC-VC) blends. ( $\square$, PBSU $100 \% ; \diamond$, PBSU $80 \%$; 9 , PBSU $60 \%$; $\triangle$, PBSU $40 \%$ )

reduction in the growth rate of PBSU by considering the concentration of the PBSU in the PVDF matrix. Since PVDF phase is already crystallized at temperatures where crystallization of PBSU occur, actual concentration of PBSU is higher than the initial volume fraction. This concentration effect compensates large reduction of the growth rate of PBSU in the matrix of PVDF. However, in this PBSU/P(VDC-VC) blends, the growth rate $G$ of PBSU decreased greatly with increasing P(VDC-VC) content. This result is to be expected for a homogeneous melt where the two components are mixed on a molecular level. This large reduction of $G$ of PBSU can be explained by the dilution of PBSU concentration on the growth front of PBSU spherulite and the increase of the viscosity of the blends by blending P(VDC-VC), which acts as a polymeric diluent in the crystallization of PBSU. Since the spherulitic growth rate $G$ of P(VDC-VC) is much slower than that of PBSU (see Figure 4), almost the whole part of $\mathrm{P}(\mathrm{VDC}-\mathrm{VC})$ component can remain as melt during the crystallization of PBSU component and this P(VDC-VC) melt acts as a diluent of PBSU in PBSU rich blends. Therefore, this PBSU/P(VDC-VC) blend is unique in that low $-T_{\mathrm{m}}$ component (PBSU) governs the overall morphology of the blends and this fact implies that the kinetic factor of crystallization is very important in crystalline/crystalline polymer blends. The spherulitic morphologies of high- $T_{\mathrm{m}}$ component (P(VDC-VC)) were also observed. However, when the fast growing front of PBSU spherulite reached a P(VDC-VC) spherulite, the growth of $\mathrm{P}(\mathrm{VDC}-\mathrm{VC})$ being arrested, while PBSU spherulites grow encircling the smaller P(VDC-VC) spherulites (see Figure 7). Moreover, the nucleation frequency of $\mathrm{P}(\mathrm{VDC}-\mathrm{VC})$ was so high that growing $\mathrm{P}(\mathrm{VDC}-\mathrm{VC})$ spherulites impinged together and growth being stopped immediately. Therefore, observing the overall spherulitic growth of P(VDC-VC) in the blends was unsuccessful. The spherulitic growth rate $G$ of pure $\mathrm{P}(\mathrm{VDC}-\mathrm{VC})$ is shown in Figure 5.

To verify the effect of kinetic factor on the morphology of the blends, we observed the morphologies of the blends with various blend compositions and crystallization temperatures. Figure 6 shows spherulitic morphology of 


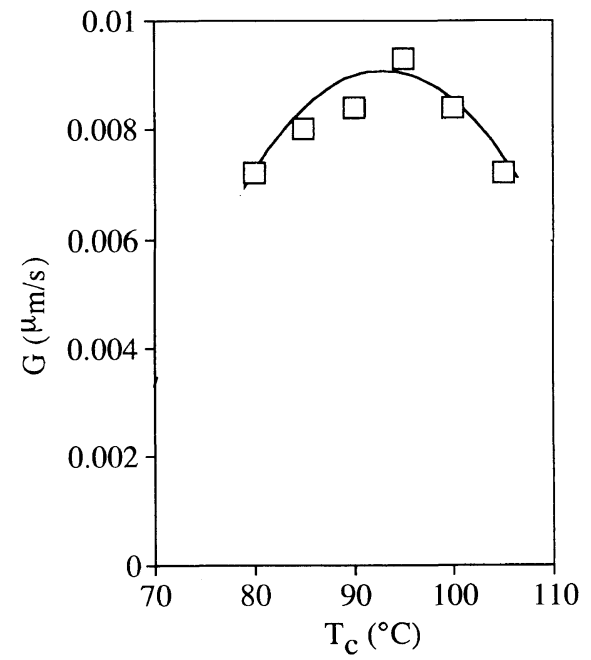

Figure 5. Spherulitic growth rate $G$ of pure $\mathrm{P}(\mathrm{VDC}-\mathrm{VC}) v s$. crystallization temperature $T_{\mathrm{c}}$.

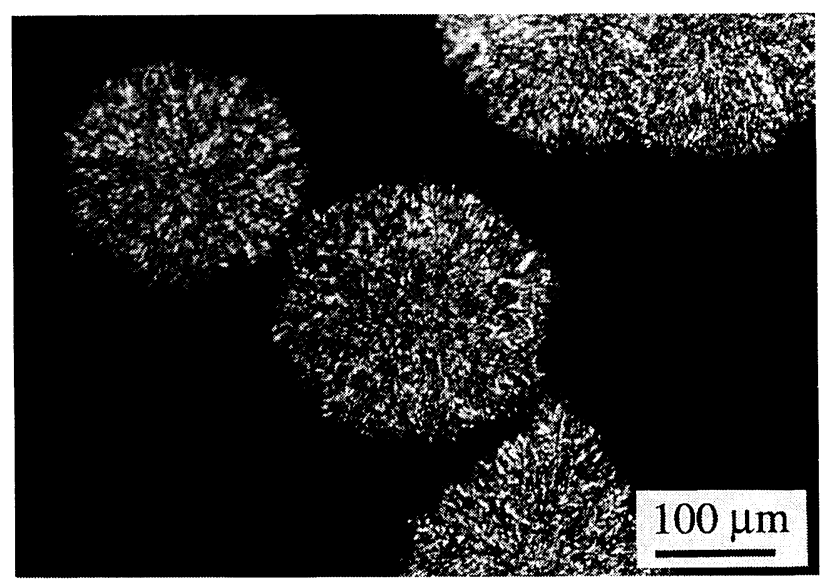

Figure 6. Optical micrograph of the spherulites of PBSU in PBSU/P(VDC-VC) $(60: 40)$ blends (A in Figure 4). Micrograph was taken after 9 min at $80^{\circ} \mathrm{C}$.

PBSU in PBSU/P(VDC-VC) $(60: 40)$ blend crystallized at $80^{\circ} \mathrm{C}$ (A in Figure 4). Since, in this blend, the PBSU-type spherulites grew so quickly (compare Figures 4 and 5) that hardly did the P(VDC-VC)-type spherulites nucleate and grew before the whole sample was filled with PBSU spherulites. Therefore, only PBSU spherulites were observed in Figure 6. However, quite different morphology was observed for the same $60: 40$ blend but crystallized at $95^{\circ} \mathrm{C}$ (B in Figure 4). In this case, the growth rate $G$ of PBSU was slowed down compared to sample A but it was still ca. 10 times faster than pure $\mathrm{P}(\mathrm{VDC}-\mathrm{VC})$. Therefore, the fast-growing PBSU spherulites continued to grow encircling the slow-growing P(VDC-VC) spherulites, while the growth of P(VDC-VC) spherulites were arrested by PBSU spherulites. With this reason, the $\mathrm{P}(\mathrm{VDC}-\mathrm{VC})$ spherulites outside of PBSU grew larger than that inside of PBSU. Figure 7(a) shows a large PBSU spherulite grown encircling the small $P(V D C-V C)$ spherulites. Since the birefringent contrast of P(VDC-VC) was so weak than that of PBSU, the observed spherulite of P(VDC-VC) looked like a dark circle. To verify that these dark circles were the spherulites of P(VDC-VC), we quenched the sample in Figure 7(a) to room temperature and observed the morphology of the blend. It is expected that the PBSU melt outside the
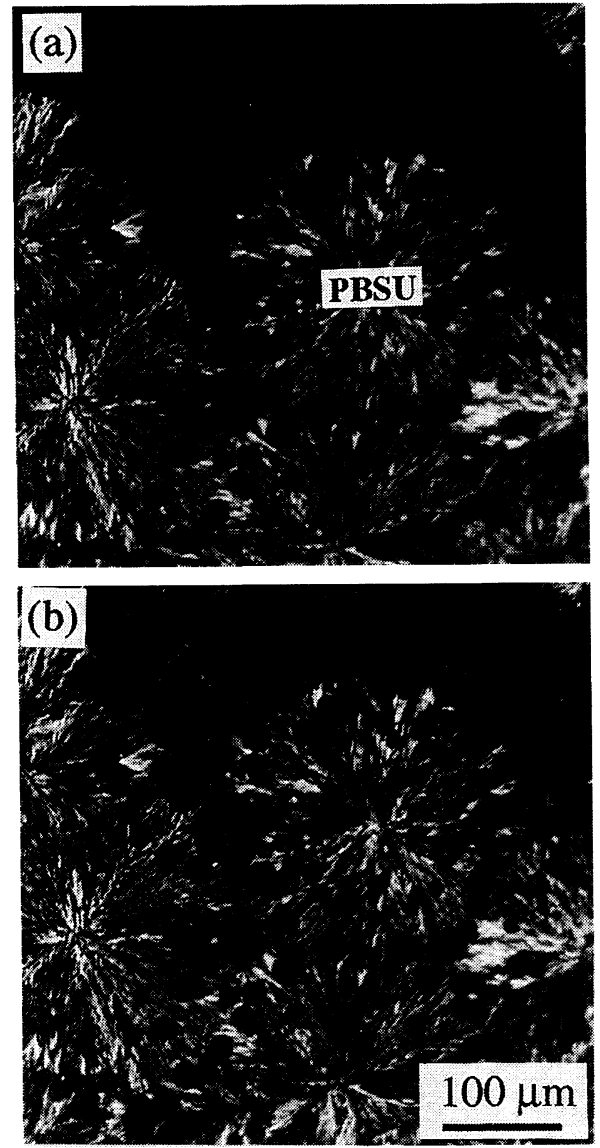

Figure 7. Optical micrographs of PBSU/P(VDC-VC) $(60: 40)$ blends (B in Figure 4) showing the spherulites grown encircling the small $\mathrm{P}(\mathrm{VDC}-\mathrm{VC})$ spherulites. (a) micrograph taken after $90 \mathrm{~min}$ at $95^{\circ} \mathrm{C}$; (b) micrograph taken immediately after the sample was cooled to room temperature. The two micrographs were taken at the same section of the sample. A sensitive-tint retardation plate in the beam was inserted at $45^{\circ}$ to the directions of the crossed polarizer and analyzer.

PBSU spherulite will crystallize in this cooling process, while less time is available for the slow-growing P(VDC-VC) melt to crystallize. Figure 7(b) showed the same section of the sample in Figure 7(a), taken immediately after the sample was quenched to room temperature. It is apparent that the dark circles outside the PBSU spherulites are the P(VDC-VC) spherulites crystallized at $95^{\circ} \mathrm{C}$ and the bright areas around these circles are PBSU crystals crystallized during cooling from $95^{\circ} \mathrm{C}$ to room temperature. Therefore, comparing Figures 7(a) and 7(b), it is clear that the dark circles observed in the PBSU spherulites (Figure 7(a)) were the spherulites of $\mathrm{P}(\mathrm{VDC}-\mathrm{VC})$ arrested by fast-growing PBSU spherulite. Figure 8 shows the morphology of PBSU/P(VDCV) $(40: 60)$ blends crystallized at $85^{\circ} \mathrm{C}(\mathrm{C}$ in Figure 3$)$. To see the small P(VDC-VC) spherulites outside the PBSU spherulite more clearly, a sensitive-tint retardation plate was inserted at $45^{\circ}$ to the directions of the crossed polarizer and analyzer. In this P(VDC-VC)-rich blend, it is clearly seen that the small P(VDC-VC) spherulites are growing outside a large PBSU spherulite. These observations provide further evidence for the origin of the dark circles inside or outside of the PBSU spherulite in Figures 7(a) and 7(b). Although the two samples in Figures 6 and 7 had the same blend composition, considerably different morphologies were observed. This 


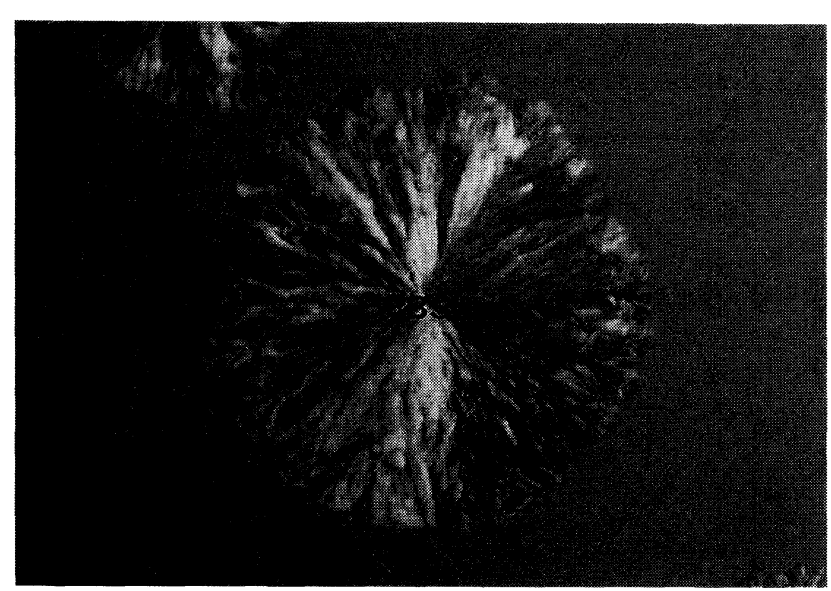

Figure 8. Optical micrograph of PBSU/P(VDC-VC) $(40: 60)$ blends (C in Figure 4) showing small P(VDC-VC) spherulites growing outside a large PBSU spherulite. Micrograph was taken after $47 \mathrm{~min}$ at $80^{\circ} \mathrm{C}$ with sensitive-tint retardation plate.
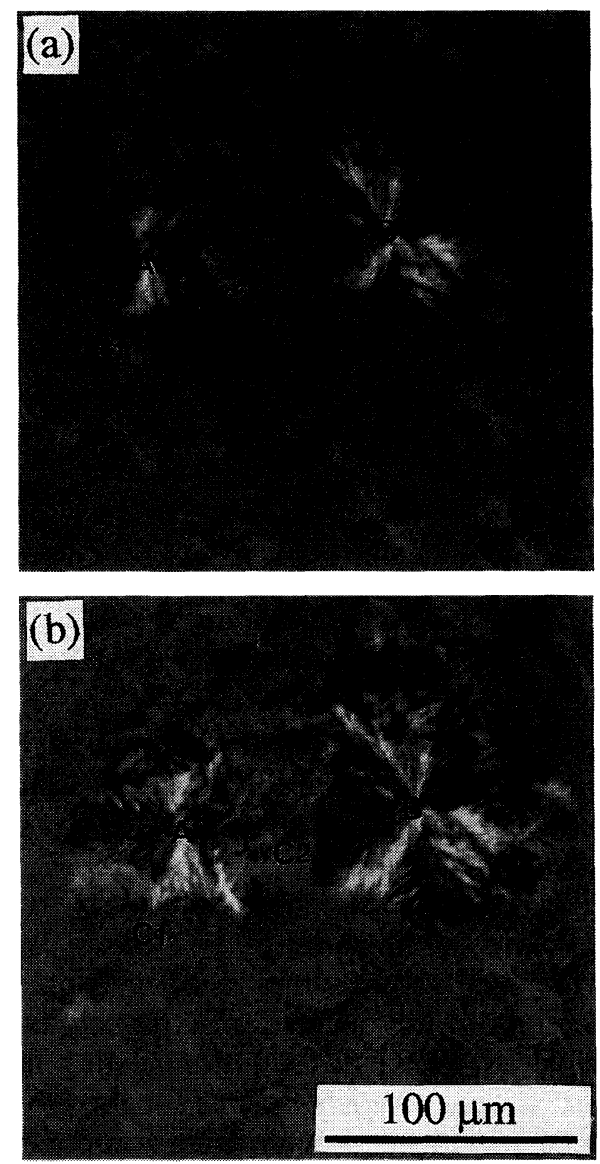

Figure 9. Optical micrographs of PBSU/P(VDC-VC) $(40: 60)$ blends (D in Figure 4) showing irregular-shaped PBSU spherulites (A and B) growing through regular $\mathrm{P}(\mathrm{VDC}-\mathrm{VC})$ spherulites (C1 and $\mathrm{C} 2$ ). (a) micrograph taken after $60 \mathrm{~min}$ at $90^{\circ} \mathrm{C}$; (b) micrograph taken after $90 \mathrm{~min}$ at $90^{\circ} \mathrm{C}$ with a sensitive-tint retardation plate. The two micrographs were taken at the same section of the sample.

fact implies that, in crystalline/crystalline polymer blends, the kinetic factor is very important in controlling the morphology of the blends.

Another interesting phenomenon occurred for the $40: 60$ blends crystallized at $90^{\circ} \mathrm{C}$ (D in Figure 4), where the growth rates of the two components were approximately the same. Figure 9(a) shows morphology of the

Polym. J., Vol. 30, No. 10, 1998 blend crystallized at $90^{\circ} \mathrm{C}$ for $60 \mathrm{~min}$. Since the growth rate of the two components are almost the same, the occasional irregular PBSU spherulites (A and B) was observed together with many P(VDC-VC) spherulites with almost the same size of PBSU. Note the growth fronts of a PBSU spherulites (A) reached P(VDC-VC) spherulites $(\mathrm{C} 1$ and $\mathrm{C} 2$ ). Figure $9(\mathrm{~b})$ shows the same section of the sample, taken after $90 \mathrm{~min}$ at $90^{\circ} \mathrm{C}$. It is clearly seen that the growth fronts of the PBSU spherulite (A) penetrated into the $\mathrm{P}(\mathrm{VDC}-\mathrm{VC})$ spherulites $(\mathrm{Cl}$ and C2). The same phenomenon was observed for the other PBSU spherulite (B). When the two different types of spherulites impinge together, in general, the growth of each component stops immediately. However, in this case, the PBSU crystalline lamellae continue to grow into $\mathrm{P}(\mathrm{VDC}-\mathrm{VC})$ spherulites. Although we have no additional experimental evidence to explain this observation, we suppose that the PBSU crystalline lamellar grew into the PBSU-enriched interlamellar regions of the P(VDC-VC) spherulites, where the PBSU molecules were excluded during the crystallization of P(VDC-VC). We can also consider another possibility, such as crystallization of segregated large PBSU domains which will be formed within the $\mathrm{P}(\mathrm{VDC}-\mathrm{VC})$ spherulites, not interlamellar regions of $\mathrm{P}(\mathrm{VDC}-\mathrm{VC})$. If $\mathrm{PBSU}$ forms segregated domains in $\mathrm{P}(\mathrm{VDC}-\mathrm{VC})$ spherulite, many bright spots of PBSU domains should be observed during the crystallization of the blend within the P(VDC-VC) spherulite (C1 and $\mathrm{C} 2$ in Figure 9). However, the growth fronts of the PBSU spherulites (A and B in Figure 9) grew almost linearly within P(VDC-VC) spherulites and no PBSU domain was observed at the outside of the growth front of the PBSU spherulites. Therefore, we suppose that the PBSU crystalline lamellar grew into the PBSU-enriched interlamellar regions of the P(VDC-VC) spherulites and the interpenetrated spherulites were possible in this PBSU/P(VDC-VC) $(40: 60)$ blends because the interlamellar regions of $\mathrm{P}(\mathrm{VDC}-\mathrm{VC})$ were thick enough to accommodate PBSU lamellae between them. A similar phenomenon so called interpenetrated spherulites or interlocked spherulites has been reported by Blumm et al. ${ }^{13}$ in PHB/PLLA system. Furthermore, Liu et al. ${ }^{17}$ recently have reported the crystallization of low- $T_{\mathrm{m}}$ component PBA in the PVDF interlamellar region by synchrotron small-angle $\mathrm{X}$-ray scattering. They concluded that PBA could crystallize as a thick lamellae in the PVDF interlamellar region and that there was a mixed amorphous phase on either side of the PBA lamellae, i.e., between the PBA and PVDF crystal lamellae. These results support our assumption in this article. It is also expected that the phenomenon of interpenetrated spherulites may be related to the improvement of some mechanical properties of bulk samples.

\section{Melting Behavior of the Blends}

Figure 10 shows DSC thermograms showing melting endotherms of the blends crystallized at a cooling rate of $1^{\circ} \mathrm{C} \mathrm{min}^{-1}$ from the melt as explained in the experimental section. Two distinct melting peaks appeared corresponding to the two specific crystalline components. The lower and the higher-melting peaks are attributed to the melting of PBSU and P(VDC-VC) phase, 


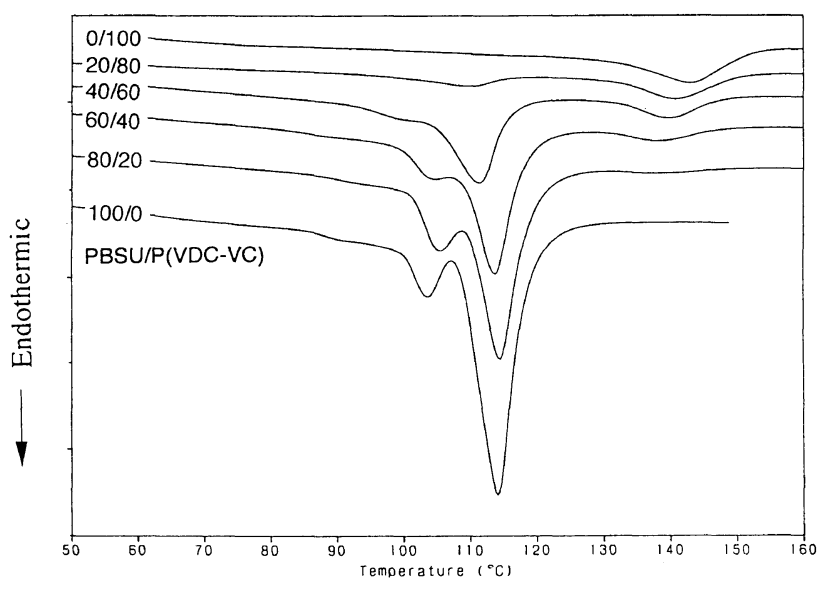

Figure 10. DSC melting endotherms of PBSU/P(VDC-VC) blends crystallized at a cooling rate of $1{ }^{\circ} \mathrm{C} \mathrm{min}^{-1}$ after maintaining at $170^{\circ} \mathrm{C}$ for $10 \mathrm{~min}$. Scan rate was $20^{\circ} \mathrm{C} \mathrm{min}^{-1}$. Each component formed segregated crystals. The higher and the lower melting peaks are attributed to the melting of $\mathrm{P}(\mathrm{VDC}-\mathrm{VC})$ and $\mathrm{PBSU}$, respectively.

Table II. The melting point $T_{\mathrm{m}}$ of solution-cast PBSU/P(VDC-VC) blends

\begin{tabular}{|c|c|c|}
\hline \multirow{3}{*}{ PBSU/P(VDC-VC) } & PBSU & $P(V D C-V C)$ \\
\hline & $T_{\mathrm{m}, \mathrm{PBSU}}$ & $T_{\mathrm{m}, \mathrm{P}(\mathrm{VDC}-\mathrm{vC})}$ \\
\hline & ${ }^{\circ} \mathrm{C}$ & ${ }^{\circ} \mathrm{C}$ \\
\hline $100: 0$ & 114.7 & - \\
\hline $80: 20$ & 114.3 & $\mathrm{ND}^{\mathrm{a}}$ \\
\hline $60: 40$ & 113.0 & 141.8 \\
\hline $40: 60$ & 112.9 & 142.3 \\
\hline $20: 80$ & 112.6 & 145.0 \\
\hline $0: 100$ & - & 147.2 \\
\hline
\end{tabular}

${ }^{a} \mathrm{ND}$, not determined (no noticable melting peak).

Table III. The melting peaks $T_{\mathrm{m}}$ of PBSU and P(VDC-VC) in PBSU/P(VDC-VC) blends.

Samples were crystallized at a cooling rate of $1^{\circ} \mathrm{Cmin}^{-1}$

\begin{tabular}{ccc}
\hline & \multicolumn{1}{c}{ PBSU } & $\frac{P(V D C-V C)}{T_{\text {PBSU/P(VDC-VC) }}}$ \\
\cline { 2 - 3 } & $\frac{T_{\mathrm{m}, \mathrm{PBSU}}}{{ }^{\circ} \mathrm{C}}$ & $\frac{T_{\mathrm{m}, \mathrm{P}(\mathrm{VDC}-\mathrm{VC})}}{{ }^{\circ} \mathrm{C}}$ \\
\hline $100: 0$ & 114.2 & - \\
$80: 20$ & 114.2 & $\mathrm{ND}^{\mathrm{a}}$ \\
$60: 40$ & 113.6 & 138.3 \\
$40: 60$ & 111.3 & 139.8 \\
$20: 80$ & 109.4 & 140.5 \\
$0: 100$ & - & 142.7 \\
\hline
\end{tabular}

${ }^{\mathrm{a}} \mathrm{ND}$, not determined (no noticable melting peak).

respectively. PBSU-rich blends showed two melting peaks of PBSU as in the case of solution-cast blends, however, the area of lower melting peaks of PBSU was smaller than that of solution-cast blends. In this extremely slow cooling condition, sufficient time is available for the slow-growing component $\mathrm{P}(\mathrm{VDC}-\mathrm{VC})$ to crystallize competitively with PBSU melt until the blends reach the temperature where the growth rate of $\mathrm{PBSU}$ becomes much faster than P(VDC-VC) (compare Figures 4 and 5). The $T_{\mathrm{m}}$ for each component decreased with

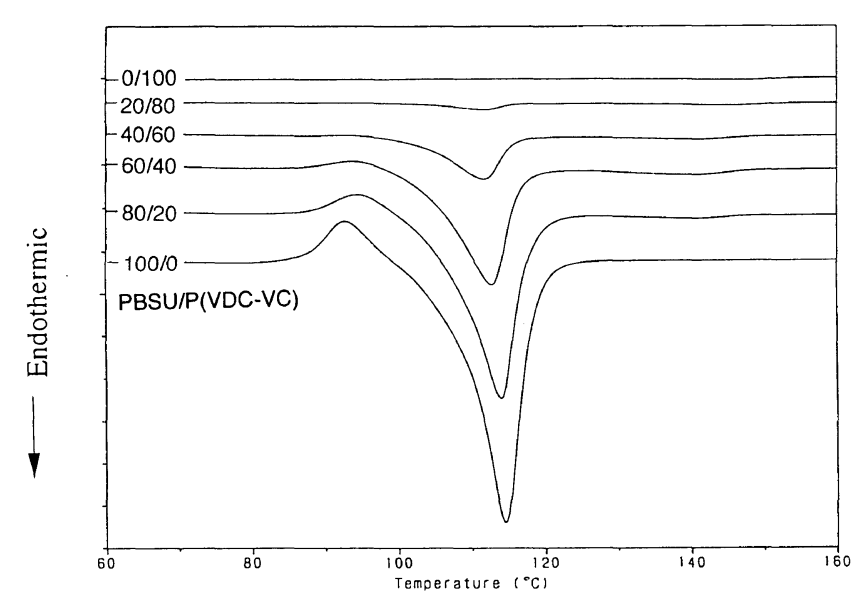

Figure 11. DSC melting endotherms of PBSU/P(VDC-VC) blends crystallized at a cooling rate of $100^{\circ} \mathrm{C} \mathrm{min}^{-1}$ after maintaining at $170^{\circ} \mathrm{C}$ for $10 \mathrm{~min}$. Only one DSC melting peaks appeared corresponding to the low $-T_{\mathrm{m}}$ component PBSU and no noticeable melting peaks appeared corresponding to the high- $T_{\mathrm{m}}$ component $\mathrm{P}(\mathrm{VDC}-\mathrm{VC})$. Scan rate was $20^{\circ} \mathrm{Cmin}^{-1}$.

Table IV. The melting peaks $T_{m}$ of PBSU and P(VDC-VC) in PBSU/P(VDC-VC) blends.

Samples were crystallized at a cooling rate of $100^{\circ} \mathrm{Cmin}^{-1}$.

\begin{tabular}{|c|c|c|}
\hline \multirow{3}{*}{ PBSU/P(VDC-VC) } & PBSU & $\mathrm{P}(\mathrm{VDC}-\mathrm{VC})$ \\
\hline & $T_{\mathrm{m}, \mathrm{PBSU}}$ & $T_{\mathrm{m}, \mathrm{P}(\mathrm{VDC}-\mathrm{VC})}$ \\
\hline & ${ }^{\circ} \mathrm{C}$ & ${ }^{\circ} \mathrm{C}$ \\
\hline $100: 0$ & 114.2 & - \\
\hline $80: 20$ & 113.8 & $\mathrm{ND}^{\mathrm{a}}$ \\
\hline $60: 40$ & 112.5 & ND \\
\hline $40: 60$ & 111.6 & ND \\
\hline $20: 80$ & 111.5 & ND \\
\hline $0: 100$ & - & ND \\
\hline
\end{tabular}

${ }^{a} \mathrm{ND}$, not determined (no noticable melting peak).

increasing the fraction of the other component. However, the melting point depression of PBSU was larger than that of solution-cast sample (Table II). The results were summarized in Table III.

Figure 11 shows DSC thermograms of the blends crystallized at a cooling rate of $100^{\circ} \mathrm{Cmin}^{-1}$ from the melt and the results were summarized in Table IV. Since the cooling rate of the blends was extremely faster than that of previous ones (i.e., solution casting or cooling at $\left.1^{\circ} \mathrm{C} \mathrm{min}{ }^{-1}\right)$, less time is available for the $\mathrm{P}(\mathrm{VDC}-\mathrm{VC})$ melt to crystallize, while fast-growing component PBSU is able to crystallize during this short crystallization time. In this extremely fast cooling condition, fast-growing component PBSU are completely crystallized before the crystallization of $\mathrm{P}(\mathrm{VDC}-\mathrm{VC})$. Therefore, the crystallization of $\mathrm{P}(\mathrm{VDC}-\mathrm{VC})$ should occur in the matrix of PBSU crystals and this inhibits the crystallization of $\mathrm{P}(\mathrm{VDC}$ VC). Therefore, only one DSC melting peak appeared corresponding to the low- $T_{\mathrm{m}}$ component PBSU and no noticeable melting peak appeared corresponding to the high- $T_{\mathrm{m}}$ component P(VDC-VC). For the most studies reported so far on the crystallization and melting behavior of crystalline/crystalline polymer blends, ${ }^{10-18}$ the high- $T_{\mathrm{m}}$ component always governed the overall crystallization of the blends. However, in this case, the 


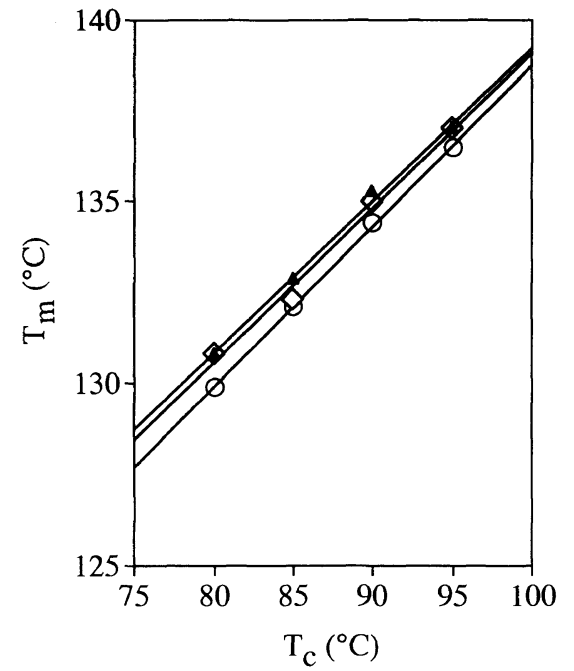

Figure 12. Hoffman-Weeks plots for $P(V D C-V C)$ in $P B S U / P(V D C-$ VC) blends. $\Delta, \mathrm{P}(\mathrm{VDC}-\mathrm{VC}) 100 \%$; $\diamond, \mathrm{P}(\mathrm{VDC}-\mathrm{VC}) \mathrm{80} \%$; O, P(VDCVC) $60 \%$.

crystallization of the high- $T_{\mathrm{m}}$ component $\mathrm{P}(\mathrm{VDC}-\mathrm{VC})$ was interrupted by the presence of the low- $T_{\mathrm{m}}$ component PBSU. It is to be noted that the kinetic factors of crystallization such as the rate of cooling should be taken into account in discussing the morphology and melting behavior of crystalline/crystalline polymer blends. Whether a specific component has high- $T_{\mathrm{m}}$ or low- $T_{\mathrm{m}}$ is not so important but a component crystallizing dominantly in the blends governs the overall morphology and melting behavior of the blends. In this sense, the result shown in Figure 11 is unique in that the crystallization of high- $T_{\mathrm{m}}$ component $\mathrm{P}(\mathrm{VDC}-\mathrm{VC})$ was seriously influenced by low- $T_{\mathrm{m}}$ component PBSU. Similar results were obtained for the blends quenched in the liquid nitrogen. In Figure 11, for the blends containing more than $60 \%$ PBSU showed exothermic peaks $\left(\mathrm{ca} .93^{\circ} \mathrm{C}\right)$ just before the melting endotherms of PBSU. We can consider two possibilities for these exothermic peaks. One is the recrystallization of unstable PBSU crystalline phase. Since these blends were crystallized extremely fast at a cooling rate of $100^{\circ} \mathrm{Cmin}^{-1}$, we supposed that unstable PBSU crystalline phase was formed during this fast cooling condition. Similar behavior was observed for PBSU crystallized at a cooling rate of $100^{\circ} \mathrm{C} \mathrm{min}-1$ in our previous study with PBSU/PVDF. ${ }^{18}$ Actually, these exothermic peaks were sensitively dependent upon the heating rate, however, we fixed scanning rate as $20^{\circ} \mathrm{Cmin}^{-1}$ to compare this data with another results, such as cooling rate of $1^{\circ} \mathrm{C} \mathrm{min}^{-1}$ (Figure 10) and the results of our previous study. ${ }^{18}$ The other possibility is the crystallization of amorphous PBSU phase itself, which were uncrystallized during such a fast cooling process. However, our previous study with PBSU/ $\mathrm{PVDF}^{18}$ showed that the cold crystallization peak temperature of quenched PBSU was $c a .70^{\circ} \mathrm{C}$. Therefore, the recrystallization of PBSU crystalline phase is more feasible in this case. For the blends crystallized during extremely slow cooling condition $\left(1^{\circ} \mathrm{C} \mathrm{min}{ }^{-1}\right)$, which could form more stable PBSU crystal showed no exothermic peaks as shown in Figure 10.

The melting point of a crystalline polymer is affected not only by thermodynamic factors but also by mor-

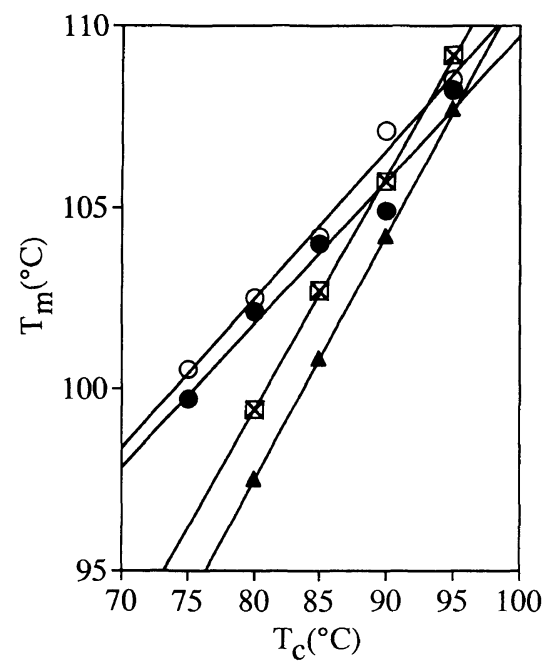

Figure 13. Hoffman-Weeks plots for PBSU in PBSU/P(VDC-VC) blends. $\boldsymbol{\Lambda}$, PBSU $100 \%$; $囚$, PBSU $80 \%$; $\bullet$, PBSU $60 \%$; $\bigcirc$, PBSU $40 \%$.

phological factors. To avoid the morphological contribution to the melting point (or melting point depression), an equilibrium melting points of the blends were analyzed and the results will be discussed in the next section.

\section{Isothermal Crystallization of the Blends}

Figure 12 shows the Hoffman-Weeks plots ${ }^{20}$ for the $\mathrm{P}(\mathrm{VDC}-\mathrm{VC})$ component in various PBSU/P(VDC-VC) blends. The DSC melting peak temperatures of the isothermally crystallized samples were used in these plots. The blends containing more than $60 \%$ of $\mathrm{P}(\mathrm{VDC}-\mathrm{VC})$ showed melting peaks of $\mathrm{P}(\mathrm{VDC}-\mathrm{VC})$. For a given blend composition, $T_{\mathrm{m}}$ of $\mathrm{P}(\mathrm{VDC}-\mathrm{VC})$ increased with $T_{\mathrm{c}}$ and straight lines were drawn. The slope $\eta$ of $\mathrm{P}(\mathrm{VDC}-\mathrm{VC})$ was almost unchanged with blend composition. However, for a given $T_{\mathrm{c}}$, no noticeable melting point depressions of $\mathrm{P}(\mathrm{VDC}-\mathrm{VC})$ were observed. $T_{\mathrm{m}}$ of P(VDC-VC) containing 20\% PBSU was the same as that of pure $\mathrm{P}(\mathrm{VDC}-\mathrm{VC})$ and $T_{\mathrm{m}}$ of $\mathrm{P}(\mathrm{VDC}-\mathrm{VC})$ containing $40 \%$ PBSU was merely $1{ }^{\circ} \mathrm{C}$ lower than that of pure $\mathrm{P}(\mathrm{VDC}-\mathrm{VC})$. Such a small reduction of $T_{\mathrm{m}}$ in miscible blends containing crystalline component is exceptional. We have reported a large equilibrium melting point depression of PHB in PHB/poly(vinylidene chloride-coacrylonitrile) $\mathrm{P}(\mathrm{VDC}-\mathrm{AN})$ blends ${ }^{9}$ where the depression of $T_{\mathrm{m}}^{\circ}$ was as large as $30^{\circ} \mathrm{C}$. We also have reported the depression of high- $T_{\mathrm{m}}$ component PVDF in PBSU/ PVDF blends where the depression was $c a .10^{\circ} \mathrm{C}$. Similar results were reported by Manley et al. ${ }^{14}$ in the case of PBA/PVDF blends. Such a small decreases of $T_{\mathrm{m}}$ of $\mathrm{P}(\mathrm{VDC}-\mathrm{VC})$ component in this case can be explained by considering the concentration of PBSU which acts as a diluent during the crystallization of P(VDC-VC). Although the samples isothermally crystallized in Figure 12 were $\mathrm{P}(\mathrm{VDC}-\mathrm{VC})$-rich blends, the growth rate of PBSU was approximately equal or still faster than $\mathrm{P}(\mathrm{VDC}-\mathrm{VC})$ depending on the crystallization conditions (see Figures 4 and 5). Therefore, the minor component PBSU phase can proceed solidification before the completion of the crystallization of $\mathrm{P}(\mathrm{VDC}-\mathrm{VC})$. This means that the actual volume fraction of $\mathrm{P}(\mathrm{VDC}-\mathrm{VC})$ melt at the growth front of $\mathrm{P}(\mathrm{VDC}-\mathrm{VC})$ spherulites is 
much higher than the initial composition and only few PBSU melt acts as a diluent of P(VDC-VC). Therefore, we suppose that this concentration effect is the main cause of a very small reduction of $T_{\mathrm{m}}$ of $\mathrm{P}$ (VDC-VC) component in this study. It is important to remember that the isothermal crystallization of the two constituent components occurred over the same temperature ranges from $75^{\circ} \mathrm{C}$ to $95^{\circ} \mathrm{C}$ as can be seen in Figures 12 and 13 .

However, the Hoffman-Weeks plots for the PBSU component was substantially different from the results of P(VDC-VC). Figure 13 shows the Hoffman-Weeks plots for the PBSU component in various PBSU/P(VDCVC) blends. The blends containing more than $40 \%$ PBSU showed noticeable melting endotherms of PBSU. For a given blend composition, $T_{\mathrm{m}}$ of PBSU increased linearly with $T_{\mathrm{c}}$ as in the case of P(VDC-VC). However, for a given $T_{\mathrm{c}}$, the value of $T_{\mathrm{m}}$ of PBSU increased with $\mathrm{P}$ (VDC-VC) content. For the blends containing $60 \%$ $\mathrm{P}(\mathrm{VDC}-\mathrm{VC})$ crystallized at $80^{\circ} \mathrm{C}, T_{\mathrm{m}}$ of the blended PBSU was as large as $5^{\circ} \mathrm{C}$ higher than pure PBSU. From the thermodynamic point of view, $T_{\mathrm{m}}$ of the blend should be lower than that of pure state. Therefore, the determination of equilibrium melting point using HoffmanWeeks plots has no meaning here. We have reported a similar phenomenon in the case of PBSU/PVDF blends. ${ }^{18}$ In PBSU/PVDF blends, we explained two possibilities: (a) concentration effect of PBSU in the growth front of PBSU spherulites and (b) melting of PBSU crystals in the solid matrix of high- $T_{\mathrm{m}}$ component PVDF. It is reasonable that the explanation (a) is applicable to the present case as in the case of P(VDCVC) component discussed in the previous paragraph. Concerning the possibility (b), we suppose the reason as follows. In this article, we have taken the value of $T_{\mathrm{m}}$ as the peak temperature of the DSC curve at a heating rate of $20^{\circ} \mathrm{Cmin}^{-1}$. Although the two components in PBSU/P(VDC-VC) blends crystallize over the same temperature range, the melting of $\mathrm{P}(\mathrm{VDC}-\mathrm{VC})$ occurs ca. $30^{\circ} \mathrm{C}$ higher than that of PBSU when we heat the isothermally crystallized sample. Therefore, the melting of low- $T_{\mathrm{m}}$ component PBSU crystals occurs in the interlamellar or interspherulitic regions of $\mathrm{P}$ (VDC-VC) spherulitites. We suppose that these solidified P(VDCVC) phase around the PBSU crystal phase obstruct the recoiling (i.e., melting) of the PBSU molecules in PBSU crystals during the DSC heating scan, which result in the delay of melting of PBSU, i.e., a raise of apparent $T_{\mathrm{m}}$ of PBSU. We suppose that the actual $T_{\mathrm{m}}$ of PBSU is much lower than the $T_{\mathrm{m}}$ of the blends appeared in Figure 13. It is clearly seen in Figure 13 that the more the amount of P(VDC-VC) phase, the larger the raise of $T_{\mathrm{m}}$ of PBSU. To verify the effect of P(VDC-VC) crystals on the $T_{\mathrm{m}}$ of PBSU (i.e., recoiling of PBSU) in the blends, we measured the $T_{\mathrm{m}}$ of isothermally crystallized blends with various heating rates. When we scan the isothermally crystallized sample very slowly (e.g., $1^{\circ} \mathrm{C} \mathrm{min}{ }^{-1}$ or less), PBSU crystals have enough time to recoiling around the real $T_{\mathrm{m}}$ of PBSU. Therefore, the measured $T_{\mathrm{m}}$ will represent approximately the real $T_{\mathrm{m}}$ of PBSU. However, such a slow scan causes recrystallization (or lamellar thickening) of PBSU during the heating scan and it was impossible to separate the effect of slow cooling which lowers the apparent $T_{\mathrm{m}}$ of PBSU from the effect of recrystallization of PBSU which raises the $T_{\mathrm{m}}$ of PBSU. In this sense, crystallization and melting behavior of low- $T_{\mathrm{m}}$ component in crystalline/crystalline polymer blend is unique and careful attentions are required in interpreting the measured value of $T_{\mathrm{m}}$ of low- $T_{\mathrm{m}}$ component.

Finally, for the origin of the miscibility appeared in this PBSU/P(VDC-VC) blends, we suppose that the attractive interactions involving the carbonyl groups of PBSU is the most probable one as in the case of other miscible blends containing polyesters mainly investigated by Coleman et al. ${ }^{21-23}$ To verify the specific interaction and the corresponding site on the P(VDC-VC), further studies on the miscibility of various blends of biodegradable polyesters with poly(vinylidene halide)s are now in progress using Fourier-transform infrared spectrophotometer with an infrared microscope.

\section{CONCLUSIONS}

The PBSU/P(VDC-VC) blends exhibited very exceptional melting behaviors and spherulitic morphologies which were different from those previously reported by other researchers for the crystalline/crystalline polymer blends, where the high- $T_{\mathrm{m}}$ component always governed the overall crystallization behavior and morphology of the blends. Spherulitic morphology and the melting behavior of the blends were strongly dependent upon the crystallization kinetics and some unique phenomena were observed: (i) in contrast to the other results reported so far, $G$ of low- $T_{\mathrm{m}}$ component (PBSU) was decreased greatly with increasing $\mathrm{P}(\mathrm{VDC}-\mathrm{VC})$ content, (ii) when the growth rate of the two components are approximately the same (i.e., for the $40: 60$ blend crystallized at $90^{\circ} \mathrm{C}$ ), blend formed so called interlocked spherulites, where PBSU spherulite is grown through the interlamellar region of $\mathrm{P}(\mathrm{VDC}-\mathrm{VC})$ spherulite, (iii) for the blends crystallized during fast cooling conditions from the melt (e.g., more than $10^{\circ} \mathrm{Cmin}^{-1}$ ), only one melting peak appeared corresponding to PBSU and no noticeable melting peaks of high- $T_{\mathrm{m}}$ component $\mathrm{P}(\mathrm{VDC}-\mathrm{VC})$ were observed. The results reported in this article provided a new insight into the crystallization and the morphology of the blends, where the two components are crystalline. It is concluded that the kinetic factors are the most important one in controlling the crystallization and the morphology of the crystalline/crystalline polymer blends, not differences in $T_{\mathrm{m}}$ or $T_{\mathrm{m}}$ itself. Therefore, for a specific crystallization condition, the low- $T_{\mathrm{m}}$ component is also able to govern the crystallization and the morphology of the blends as shown in this article.

Acknowledgment. The authors would like to thank Mr. T. Morioka and his research group in TOUNEN CHEMICAL CORP. for synthesizing the biodegradable polyester PBSU and Asahi Kasei for provision of $\mathrm{P}(\mathrm{VDC}-\mathrm{VC})$.

\section{REFERENCES}

1. T. Nishi and T. T. Wang, Macromolecules, 8, 909 (1975).

2. C. J. Ong and F. P. Price, J. Polym. Sci., Polym. Symp., 63, 45 (1978).

3. C. J. Ong and F. P. Price, J. Polym. Sci., Polym. Symp., 63, 59 (1978). 
4. S. Nojima, K. Watanabe, Z. Zheng, and T. Ashida, Polym. J., 20, 823 (1988).

5. R. S. Barnum, J. W. Barlow, and D. R. Paul, J. Appl. Polym. Sci., 27, 4065 (1982).

6. E. G. Lezcano, C. Salom Coll, and M. G. Prolongo, Polymer, 37, 3603 (1996).

7. E. D. Paglia, P. L. Beltrame, M. Canetti, A. Seves, B. Marcandalli, and E. Martuscelli, Polymer, 34, 996 (1993).

8. P. Greco and E. Martuscelli, Polymer, 30, 1475 (1989).

9. J. C. Lee, K. Nakajima, T. Ikehara, and T. Nishi, J. Polym. Sci., Part B, Polym. Phys., 35, 2645 (1997).

10. M. Aubin, Y. Bedard, M. F. Morrissette, and R. E. Prud'homme, J. Polym. Sci., Part B, Polym. Phys., 21, 233 (1983).

11. H. Zhang and R. E. Prud'homme, J. Polym. Sci., Part B, Polym. Phys., 24, 723 (1987).

12. M. Avella and E. Martuscelli, Polymer, 29, 1731 (1988).

13. E. Blumm and A. J. Owen, Polymer, 36, 4077 (1995).
14. J. P. Penning and R. St. John Manley, Macromolecules, 29, 77 (1996).

15. J. P. Penning and R. St. John Manley, Macromolecules, 29, 84 (1996).

16. K. Fujita and T. Kyu, Macromolecules, 29, 91 (1996).

17. L.-Z. Liu, B. Chu, J. P. Penning, and R. St. John Manley, Macromolecules, 30, 4398 (1997).

18. J. C. Lee, H. Tazawa, T. Ikehara, and T. Nishi, Polym. J., 30 , 327 (1998)

19. T. G. Fox, Bull. Am. Phys. Soc., 1, 123 (1956).

20. J. D. Hoffman and J. J. Weeks, J. Res. Natl. Bur. Stand., 66, 13 (1962).

21. M. M. Coleman and J. Zarian, J. Polym. Sci., Part B, Polym. Phys., 17, 837 (1979).

22. D. F. Varnell and M. M. Coleman, Polymer, 22, 1324 (1981).

23. D. F. Varnell, J. P. Runt, and M. M. Coleman, Polymer, 24, 37 (1983). 